\title{
Lactate production yield from engineered yeasts is dependent from the host background, the lactate dehydrogenase source and the lactate export
}

\author{
Paola Branduardi ${ }^{1}$, Michael Sauer ${ }^{2,3}$, Luca De Gioia ${ }^{1}$, Giuseppe Zampella ${ }^{1}$, \\ Minoska Valli2,3, Diethard Mattanovich 2,3 and Danilo Porro*1
}

Address: ${ }^{1}$ Università degli Studi di Milano - Bicocca, Dipartimento di Biotecnologie e Bioscienze, P.zza della Scienza 2, 20126 Milano, Italy, 2Institute of Applied Microbiology, BOKU - University of Natural Resources and Applied Life Sciences, Muthgasse 18, A-1190 Wien, Austria and ${ }^{3}$ Fh-campus wien - University of Applied Sciences, School of Bioengineering, Muthgasse 18, A-1190 Wien, Austria

Email: Paola Branduardi - paola.branduardi@unimib.it; Michael Sauer - michael.sauer@fh-campuswien.ac.at; Luca De

Gioia - luca.degioia@unimib.it; Giuseppe Zampella - giuseppe.zampella@unimib.it; Minoska Valli - minoska.valli@boku.ac.at;

Diethard Mattanovich - diethard.mattanovich@boku.ac.at; Danilo Porro* - danilo.porro@unimib.it

* Corresponding author

Published: 30 January 2006

Microbial Cell Factories 2006, 5:4 doi:10.1 186/1475-2859-5-4
Received: 28 November 2005

Accepted: 30 January 2006

This article is available from: http://www.microbialcellfactories.com/content/5/I/4

(c) 2006 Branduardi et al; licensee BioMed Central Ltd.

This is an Open Access article distributed under the terms of the Creative Commons Attribution License (http://creativecommons.org/licenses/by/2.0), which permits unrestricted use, distribution, and reproduction in any medium, provided the original work is properly cited.

\begin{abstract}
Background: Metabolic pathway manipulation for improving the properties and the productivity of microorganisms is becoming a well established concept. For the production of important metabolites, but also for a better understanding of the fundamentals of cell biology, detailed studies are required. In this work we analysed the lactate production from metabolic engineered Saccharomyces cerevisiae cells expressing a heterologous lactate dehydrogenase $(L D H)$ gene. The $L D H$ gene expression in a budding yeast cell introduces a novel and alternative pathway for the $\mathrm{NAD}^{+}$regeneration, allowing a direct reduction of the intracellular pyruvate to lactate, leading to a simultaneous accumulation of lactate and ethanol.
\end{abstract}

Results: Four different $S$. cerevisiae strains were transformed with six different wild type and one mutagenised $L D H$ genes, in combination or not with the over-expression of a lactate transporter. The resulting yield values (grams of lactate produced per grams of glucose consumed) varied from as low as 0,0008 to as high as $0.52 \mathrm{~g} \mathrm{~g}^{-1}$. In this respect, and to the best of our knowledge, higher redirections of the glycolysis flux have never been obtained before without any disruption and/or limitation of the competing biochemical pathways.

Conclusion: In the present work it is shown that the redirection of the pathway towards the lactate production can be strongly modulated by the genetic background of the host cell, by the source of the heterologous Ldh enzyme, by improving its biochemical properties as well as by modulating the export of lactate in the culture media.

\section{Background}

Metabolic engineering can be defined as the directed improvement of product formation or cellular properties through the modification of specific biochemical reactions or introduction of new ones with the use of recombinant DNA technology. Aimed to produce single 
compounds, metabolic engineering necessarily includes the modification of the cellular pathway(s) as well as the redirection of the energy toward the production itself (see for a review [1]). The existing metabolic engineering applications are the result of more than two decades of global experience developing processes for the production of fine chemicals, vitamins, nutraceuticals and animal nutritional supplements such as amino acids (as examples, see [2-5]). Given their relatively low complexity, the first biotechnological applications have been developed in microorganisms.

Different research teams have been involved in the production of lactate from metabolic engineered yeasts such as Saccharomyces cerevisiae [6-13], Kluyveromyces lactis $[14,15]$, Torulaspora delbrueckii [16] and Zygosaccharomyces bailii [17]. L-Lactic acid, first discovered by the Swedish chemist Scheele (1780), has been traditionally used as a food preservative and food flavoring compound [18]. Recently, it has received attention since it can be used to produce a biodegradable polymer with plastic properties. The market for this organic acid is rapidly growing, exceeding several hundred million dollars annually [10]. This carboxylic acid is currently mainly produced using lactic-acid bacteria, such as various Lactobacillus species,(via an, anaerobic fermentation that operates optimally at $\mathrm{pH}$ values where the salt of the organic acid rather than the free acid is formed, although free lactic acid is preferred for most industrial processes [18]. The use of microorganisms like yeasts that are more tolerant to low $\mathrm{pH}$ values than the current production organisms, could strongly decrease the amount of neutralizing agents required and lower the cost of down-stream processing. Pyruvate is the end product of glycolysis; it can be further metabolized either by the pyruvate dehydrogenase complex (Pdh, EC 1.2.4.1) to acetyl-coenzyme A or by pyruvate decarboxylase (Pdc, EC4.1.1.1) to acetaldehyde and subsequently to ethanol. In previous works it has been shown that the expression of a heterologous lactate dehydrogenase (Ldh, EC 1.1.1.27) gene in the above mentioned yeast hosts introduces a new and alternative pathway for the $\mathrm{NAD}^{+}$regeneration, allowing a direct reduction of the intracellular pyruvate to lactate leading to a simultaneous formation of ethanol and lactic acid [7]. Only following a partial or a full replacement of the ethanol production by the lactate production, obtained in recombinant yeast cells lacking the Pdc and/or Pdh activities, it has been possible to obtain lactate production with high yield (max reported yield: 0.85 , i.e., gram of lactate produced per gram of glucose consumed) values [15]. Theoretically, 2 moles of lactate and 2 moles of ATP are formed per mole of glucose consumed. In the present work we show that in S. cerevisiae cells, the yield value can be strongly modulated by the genetic background of the host, by the source of the heterologous Ldh enzymes, by improving their biochemical properties as well as by modulating the export of lactate in the culture media. Following all these approaches we have been able to improve the yield from values as low as 0,0008 to values as high as 0.52 without any modulation of the Pdc and/or Pdh activities.

\section{Results and discussion Expression of different $L D H(s)$ in different yeast hosts}

Lactic acid has been already produced by metabolically engineered yeast hosts (see Introduction). To better understanding the modulation of lactate production from the background of wild type $S$. cerevisiae cells, we firstly tested lactate production from different $S$. cerevisiae yeast strains transformed with the same integrative plasmid, pB1. As a model $L D H$ gene we chose the mammalian LdhA lactate dehydrogenase. The transcription of the heterologous gene is under the control of the strong constitutive S. cerevisiae TPI (Triose Phosphate Isomerase) promoter.

Table I: Plasmids (all integrative) utilized in this study*

\begin{tabular}{|c|c|c|c|c|}
\hline Vector & Promoter & Heterologous protein & Selection marker & Reference \\
\hline $\mathrm{pBI}$ & ScTPI & BtLDH & URA3 & this study \\
\hline $\mathrm{pB} 2$ & ScTPI & $B t L D H$ & HIS3 & this study \\
\hline $\mathrm{pB} 3$ & ScTPI & BtLDH & LEU2 & this study \\
\hline PBME2 & ScTPI & $B m L D H$ & URA3 & this study \\
\hline pBST2 & ScTPI & BsLDH & URA3 & this study \\
\hline pLC5 & ScTPI & LcLDH & URA3 & Brambilla et al., 1999 \\
\hline pLC7 & ScTPI & LcLDH & HIS3 & Brambilla et al., 1999 \\
\hline p022TLP & ScTPI & $L p L D H$ & HIS3 & this study \\
\hline p0I2TLP & ScTPI & LpLDH & URA3 & this study \\
\hline p022TLPD94G & ScTPI & LpLDHD94G & HIS3 & this study \\
\hline P0I2TLPD94G & ScTPI & LpLDHD94G & URA3 & this study \\
\hline p0I2Jen I & ScTPI & ScJen I & URA3 & this study \\
\hline p022Jen I & ScTPI & Scjen I & HIS3 & this study \\
\hline
\end{tabular}

*a complete description of plasmids construction is given in Materials and Methods

Abbreviations: Sc: S. cerevisiae; Bt: Bos taurus; Bm: Bacillus megaterium Bs: Bacillus stearothermophylus; Lc: Lactobacillus casei; Lp: Lactobacillus plantarum 
The resulting expression vector has been used to transform five different $S$. cerevisiae host strains. Transformed strains have been grown in batch shake-flask culture on $2 \% \mathrm{wv}^{-1}$ glucose-YNB based media. Further, to better understand the modulation of the production from different $\operatorname{Ldh}(\mathrm{s})$, we also tested the lactate production from the same S. cerevisiae yeast strain (GRF18U) transformed with the same integrative expression vector, but bearing different $\operatorname{Ldh}(\mathrm{s})$.

Table 2 compares the lactate and the ethanol productions obtained. Independently from the yeast strain used and of the heterologous enzyme, the highest accumulation of lactate and ethanol were observed at the beginning of the stationary phase (reached, in these growth conditions, after about 30 hours from the inoculum), in coincidence with the exhaustion of glucose (data not shown; see for example also figure $1 \mathrm{~A}$ and $1 \mathrm{~B}$ ). Findings reported indicate that the lactate production is strongly dependent from the background of the hosts. Furthermore, a higher lactate production comes along with a lower ethanol accumulation (data not shown). Productions ranging from 20 to $801 \mathrm{mg} \mathrm{l}^{-1}$ have been obtained from different yeast hosts expressing one copy of the same bovine Ldh and yielding similar specific activities (ranging from 0,4 to 0,6 $\left.\mathrm{U} \mathrm{mg}^{-1}\right)$. If two or three gene copies are expressed, the product levels (up to $1110 \mathrm{mg} \mathrm{l}^{-1}$ ) and activity (up to 0,8 $\mathrm{U} / \mathrm{mg}$ ) increase, even if the improvement not proportional to the gene copy number. Data reported in the Table 2 further indicate that different Ldh(s) lead to different lactate productions (from 20 to $6150 \mathrm{mg} \mathrm{l}^{-1}$ ). On one side it is interesting to underline that, despite the high $\mathrm{Km}$ value for pyruvate, high productions (4160 $\mathrm{mg} \mathrm{l}^{-1}$ ) have been observed transforming the GRF18U yeast host with the Lactobacillus casei Ldh gene. On the other side, lactate concentrations of the same order $\left(6150 \mathrm{mg} \mathrm{l}^{-1}\right)$ have been obtained using the fructose1-6BP independent $L$. plantarum Ldh, which has a much lower Km value (Table 2).

In general, and as expected, it can be concluded that the higher the specific activity is, the more efficient is the conversion of pyruvate to lactate.

Similar results have been obtained transforming the host cells with identical centromeric plasmids bearing different Ldh(s) under the control of the same ScTPI promoter (data not shown).

\section{Improving lactate production and yield by protein engineering}

The Ldh enzyme is composed of four identical subunits [19]. All the bacterial Ldh enzymes listed in Table 2, with the exception of the L. plantarum Ldh, require fructose 1$6 \mathrm{BP}$ as a cofactor. It has been proposed that the rate limiting step of the enzymatic reaction corresponds to the conformational rearrangement of the so-called catalytic loop [20]. In particular, the movement of the catalytic loop is necessary to allow pyruvate binding and L-lactate release.

Looking at a computational development of a better Ldh enzyme, we initially took into consideration the spiny

Table 2: Lactate and ethanol productions from different S. cerevisiae hosts transformed with different Ldh(s).

\begin{tabular}{|c|c|c|c|c|c|c|c|}
\hline & plasmid & LDH & Lactate & EtOH & Yield & LDH activity & LDH Km \\
\hline Strains & & (source) & $\mathrm{mg} \mathrm{l}^{-1}$ & $\mathrm{mg} \mathrm{l}^{-1}$ & $\mathrm{~g} \mathrm{~g}^{-1}$ & $\mathrm{U} \mathrm{mg}^{-1}$ & $\mathrm{mM}$ \\
\hline W303-IA & $\mathrm{pBI}$ & B. taurus & 20 & 6430 & 0,0010 & 0,4 & $1,00[19]$ \\
\hline CEN.PK & $\mathrm{pBI}$ & B. taurus & 140 & 6340 & 0,0070 & 0,5 & 1,00 \\
\hline GRFI8U & $\mathrm{pBI}$ & B. taurus & 801 & 5750 & 0,0401 & 0,6 & 1,00 \\
\hline MBII & pLC5 & L. casei & 200 & 6110 & 0,0100 & $\mathrm{Nd}$ & $10,00[19]$ \\
\hline GRFI8U & $\mathrm{pBI} ; \mathrm{pB} 2$ & B. taurus & 950 & 5730 & 0,0475 & 0,7 & 1,00 \\
\hline GRFI8U & $\mathrm{pBI} ; \mathrm{pB} 2 ; \mathrm{pB} 3$ & B. taurus & 1100 & 5648 & 0,0550 & 0,8 & 1,00 \\
\hline GRFI8U & PBST2 & B. stearotherm. & 128 & 6310 & 0,0064 & 0,6 & $0,03[19]$ \\
\hline GRFI8U & PBME2 & B. megaterium & $137 \mid$ & 5672 & 0,0686 & 0,7 & Nd \\
\hline GRFI8U & pLC5 & L. casei & 4160 & 4270 & 0,2080 & 5,5 & 10,00 \\
\hline GRFI8U & p022TLP & L. plantarum & 6150 & 3730 & 0,3075 & 3,2 & I,50 (this study) \\
\hline
\end{tabular}

All the indicated recombinant yeast strains, together with the respective control here not reported, have been grown in shake-flasks on $2 \%$ (w/v) glucose-YNB based media till stationary phase, reached after about 30 hours after the inoculum. Cultures were independently repeated, after the screening of independent transformants, (at least) three times, rising to comparable results. In the table one fermentation per each set of experiment is reported, being the independent kinetics reproducible among themselves.

Lactate and ethanol production ( $\mathrm{mg} \mathrm{l}^{-1}$, columns 4 and 5 , respectively) correspond to the highest measured production levels.

The Yield value (column 6 ) represents the grams of lactate produced per gram of glucose consumed (max theoretical yield $=1$ ).

Ldh activity (column 7) has been determined at the highest lactate production level.

$\mathrm{Km}$ values against NADH are comprised between $0.00 \mathrm{I}$ and $0.0045 \mathrm{mM}$ [19].

$\mathrm{Km}$ apparent value of mitocondrial pyruvate transporter is $0,3 \mathrm{mM}$ [44]

Nd: not determined. 

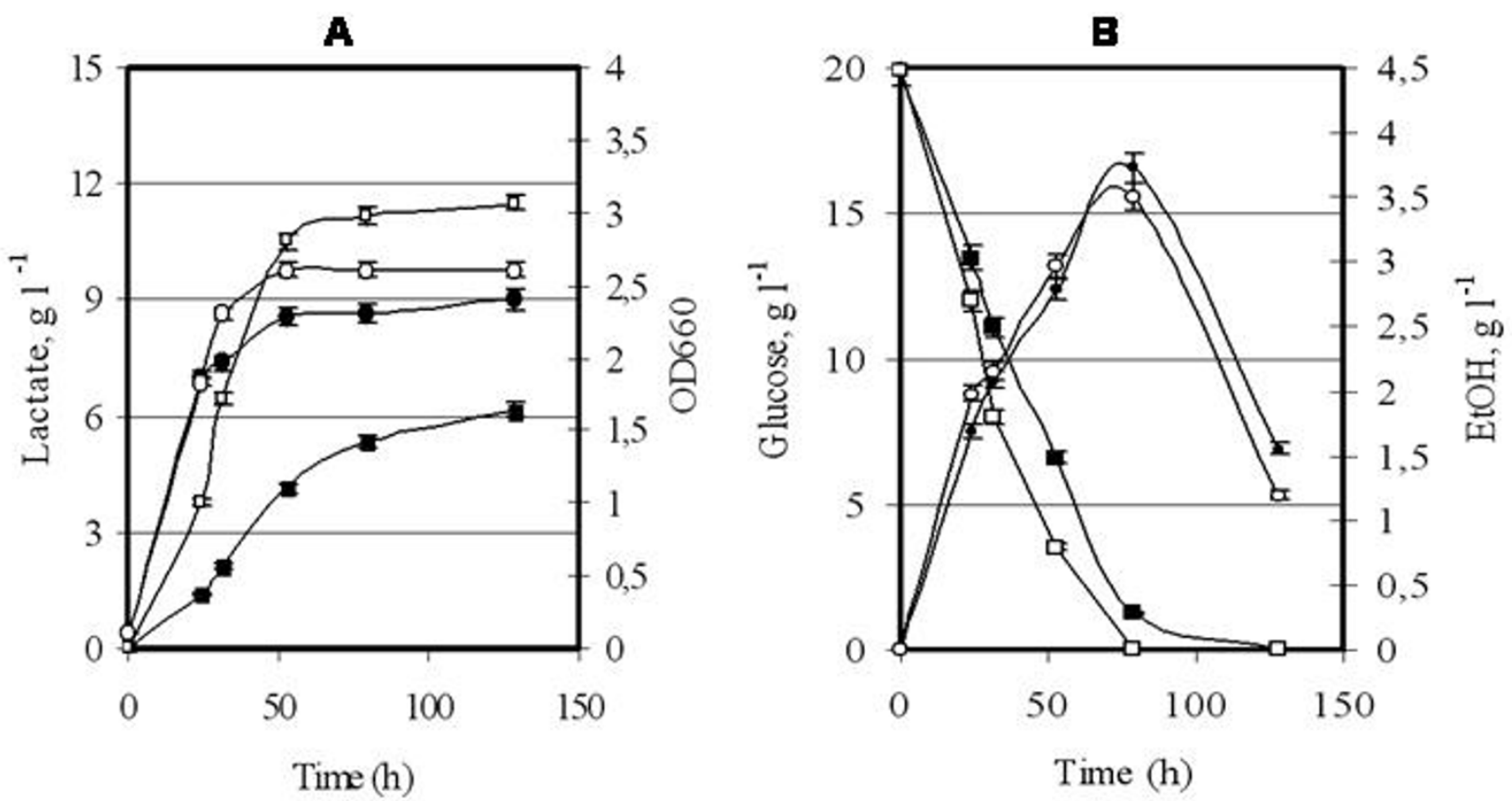

Figure I

Wild type Vs mutated Ldh. Recombinant S. cerevisiae GRFI8U cells expressing the wild type (closed symbols) or mutated (open symbols) L. plantarum LDH genes were shake-flask grown in glucose $2 \% \mathrm{wv}^{-1}$ minimal selective medium till stationary phase. Samples were collected at indicated times for optical density (OD $660 \mathrm{~nm}$, circles; panel A), lactate ( $\mathrm{l}^{-1}$, squares; panel $\mathrm{A})$, ethanol ( $\mathrm{g} \mathrm{I}^{-1}$, circles; panel $\mathrm{B}$ ) and residual glucose $\left(\mathrm{g} \mathrm{I}^{-1}\right.$, squares; panel $\mathrm{B}$ ) determinations.

dogfish (Squalus acanthias) Ldh protein. This enzyme was selected because the spatial structure of the enzyme, which is required for the docking simulations, is available in literature [21]. Because of the high sequence similarity with Ldh proteins from other sources, simulations data can be extended to the other enzymes of this family. The comparison between the X-ray structures of the apo and holo form of Ldh from $S$. acanthias reveals that the aminoacid Asn 108 could play a relevant role in the dynamic behaviour of the catalytic loop. The effect of Asn108 replacement on the potential energy profile related to the conformational rearrangement of the catalytic loop has been evaluated in silico, according to the procedure outlined in Methods. In particular, the computational investigation of five Ldh mutants in which Asn 108 has been replaced by Asp, Ala, Gly, Lys or His suggests that the Asn108/Gly replacement should lower the energy barrier of the rate determining step, possibly leading to a catalytically more efficient Ldh. In light of these computational results, we produced a mutated $L$. planctarum Ldh where the aminoacid Asp94, (corresponding to Asn108 of the S. acanthias enzyme), is replaced by Gly.

Initially we cloned the new $L D H$ gene into an integrative expression vector under the control of the constitutive
ScTPI promoter (Table 1). The GRF18U S. cerevisiae strain has been transformed. Lactate production from the new Ldh and the wild-type L. plantarum Ldh (i.e., the control) enzymes were compared, Figure 1A, B. The yeast clones obtained after transformation with the new $L D H$ gene yielded a much higher lactate accumulation (11300 against $\left.6150 \mathrm{mg} \mathrm{l}^{-1}\right)$ and productivity $\left(240 \mathrm{mg} \mathrm{l}^{-1} \mathrm{~h}^{-1}\right.$ against $90 \mathrm{mg} \mathrm{l}^{-1} \mathrm{~h}^{-1}$ as determined during the exponential growth phase).

Additionally, comparable results have been obtained transforming the host cells with two identical centromeric plasmids bearing the wild-type (i.e., control) or the mutated $L D H$ gene under the control of the same ScTPI promoter (data not shown).

In principle, the improved production level and productivity rate could be at least associated with a better transcription rate of the mutated $L D H$ gene, and/or to a lower turnover rate of the transcript, and/or to a better translation rate of the transcript and/or to a lower turnover rate of the protein. Since Ldh antibodies are not commercially available, to address these general considerations, we developed (see MM section) a polyclonal antibody against the L. plantarum Ldh protein. The amounts of the 

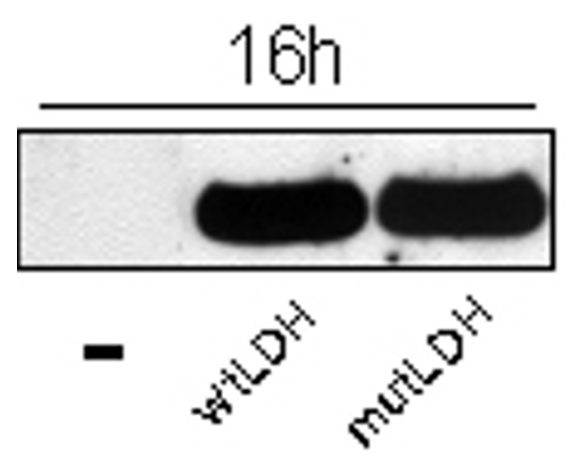
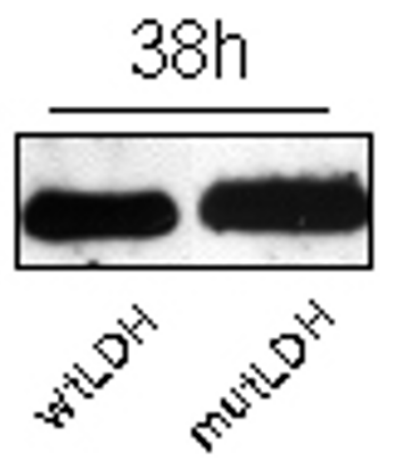
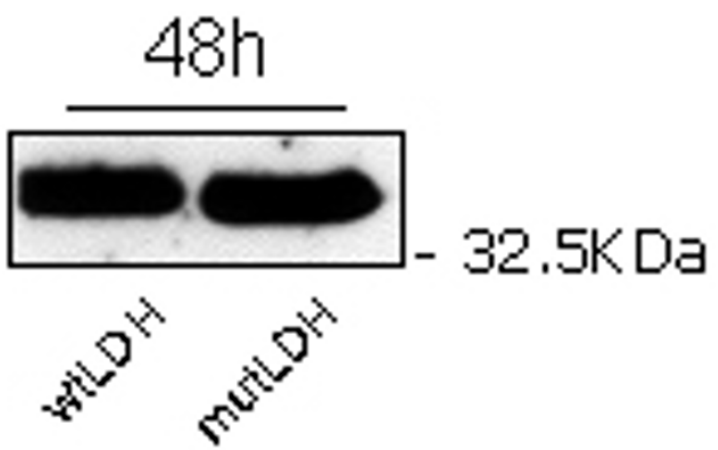

Figure 2

Comparison of wild type and mutated L. plantarum Ldh protein levels: Western Blot determination. S. cerevisiae GRFI8U cells transformed with the plasmid carrying the wild type or the mutated L. plantarum LDH genes were shake-flask grown in glucose $2 \% \mathrm{wv}^{-1}$ minimal selective medium. From samples collected at indicated times total protein were TCA extracted and Ldh(s) levels were visualised by Western Blot analyses. Protein extracts corresponding to $10^{7}$ cells were loaded in each lane, together with a negative control (-).

wild type and mutated proteins were evaluated along the growth curves of the recombinant hosts. We also determined the Ldh specific activities. On one side, Figure 2 clearly indicates that the amounts of the wild-type and mutated Ldh protein synthesized by the transformed GRF18U strain are similar. On the other side, the specific activity and the deduced $\mathrm{Km}$ value (calculated on crude cell extracts), of the mutated enzyme are different from those determined for the wild-type one, being 9,9 $\mathrm{U} \mathrm{mg}^{-1}$ and 1,01 mM against 3,2 $\mathrm{U} \mathrm{mg}^{-1}$ and 1,504 $\mathrm{mM}$, respectively. The higher activity and the lower Km justify the higher lactate accumulation and the consequently much higher yield on glucose: 0,525 against 0,3075 grams of lactate produced per gram of glucose consumed, respectively. Surprisingly, the mutated Ldh did also lead to a similar ethanol production (Fig. 1A) and to a slightly better biomass production (Fig. 1A); these findings can be associated with a higher specific glucose consumption rate (Fig. 1B).

\section{Overexpression of JENI in yeast hosts producing different amounts of lactate}

Wild type S. cerevisiae cells do not produce lactic acid; however, lactate can be used as carbon and energy source [22]. Lactic acid can freely diffuse through the membranes only in its undissociated form. Since yeast cells can grow on lactate even at $\mathrm{pH}$ values much higher than the pKA value of the organic acid (i.e., 3,78), a specific transporter should be involved in the uptake of lactate. In S. cerevisiae, synthesis of a lactate permease takes place after transcription of the JEN1 gene. Transcription of JEN1 is induced by lactate and it is repressed by glucose [23-25]. Jen 1 is the only $S$. cerevisiae member of the sialate-proton symporters subfamily belonging to the major facilitator superfamily [26].

It has been already shown that the over-expression of JEN1 in both S. cerevisiae and Pichia pastoris resulted in an increased activity of the lactate (inward) transport, while the deletion of JEN1 impaired the growth on both lactate and pyruvate [27]. A copy of JEN1 under the control of the constitutive GAPDH (glyceraldehyde-3-phosphate dehydrogenase) promoter has been introduced in S. cerevisiae cells using a centromeric plasmid; independently of the mechanisms of repression and degradation previously reported for the JEN1 gene and Jen1 protein, the cloning under a strong promoter allowed the constitutive expression of the JEN1 gene even in the presence of glucose [27].

Theoretically, higher lactate productions could be obtained by facilitating the lactate export. In fact, since the cytoplasmic $\mathrm{pH}$ value in yeast cells is much higher than the lactic acid pKa value, almost all of the lactic acid produced is in the dissociated form and has to be actively transported outside the cells. A limitation of lactic acid transport will inevitably lead to an increase in the cytoplasmic lactate concentration, inhibiting the "in vivo" Ldh activity and leading to the reduction or arrest of the lactate production. Indeed, Figure 3 proves that "in vitro" a lactate concentration as low as $10 \mathrm{~g} \mathrm{l}^{-1}$ reduces the overall $\mathrm{Ldh}$ activity by about $40 \%$. It can be speculated that the Jen 1 permease could transport lactate $/ \mathrm{H}^{+}$across the two sides of the plasma membranes depending on their concentrations. 


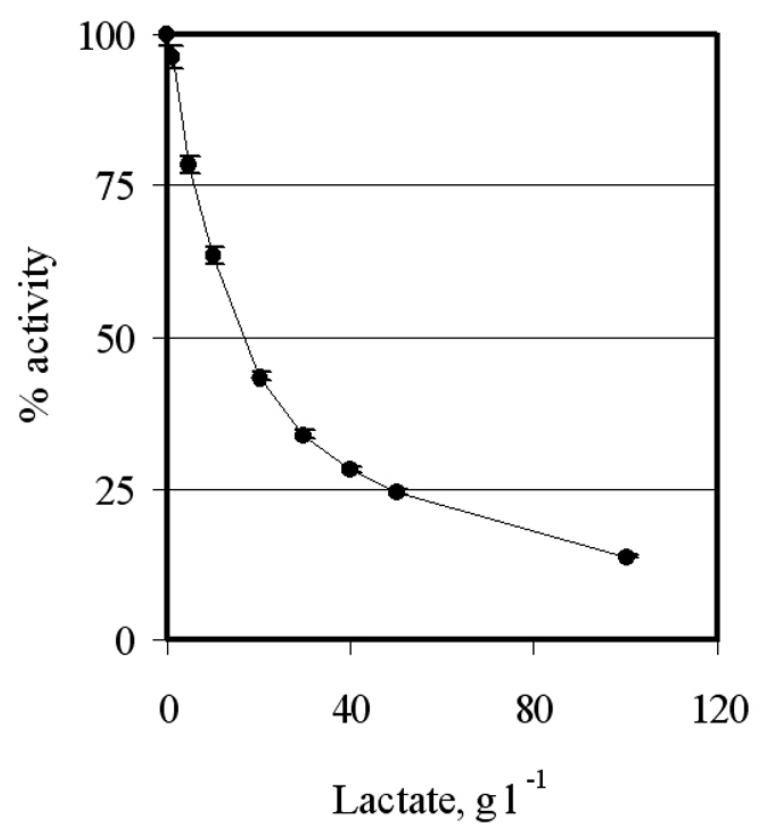

Figure 3

"In vitro" inhibition of the Ldh activity by the substrate (lactate). Total cell proteins were extracted from GRFI8U hosts cells expressing the bovine $L D H$ gene. The same amount of protein extract was used to determine the Ldh activity in presence of different amounts of lactate (abscissa) and referred as percentage (ordinate) of the Ldh activity determined in absence of lactate (control).

Based on these considerations and looking to increase lactate export and production, we co-expressed the JEN1 and $L D H$ genes in S. cerevisiae host cells growing on $2 \%$ glucose-YNB. The first findings obtained for the GRF18U yeast strain transformed with the bovine, the L. casei or the L. plantarum $L D H$ genes showed that the co-expression of JEN1 was associated with an increase of both lactate production and yield. An example of such an improvement is shown in Figure 4. Results reported in the figure seem to indicate that the extracellular accumulation of the produced lactate could be modulated by the over-expression of the Jen 1 permease. To test this hypothesis, we checked the lactate production from yeast host transformed with a $L D H$ gene and deleted of the endogenous JEN1 gene. When we compared the lactate production from wild type and jen 1 strains transformed with a $L D H$ gene, no differences were observed (data not shown). Since lactate can not diffuse through the membranes, this simple observation indicates that at least another lactate transporter must be operative.
To further investigate the effect of the co-over-expression of $L D H$ and of the JEN1 genes, we grew different recombinant yeast strains on glucose $5 \%$-YNB. Essentially, an increase of the carbon source availability (from 2 to $5 \%$ $\mathrm{wv}^{-1}$ ) simply leads to an increased lactate production. Figure 5 reports the improvements associated to the overexpression of JEN1 against the total lactic acid production from different yeast strains transformed with the $L$. case $i$ or the L. plantarum LDH genes. The improvement value, for any test, is the ratio between the amount of lactate produced by the yeast strain co-over-expressing JEN1 and $L D H$ and the same strain expressing only the $L D H$ gene (i.e., control). A value of 1 means that an identical lactate production was observed, a value of 1.5 means a $50 \%$ higher production, a value of 2 means a double production, and so on. From the analysis of the data it can be easily evinced that co-over-expression of JEN1 has a clear effect when the production of lactate is very low. However, the effect of Jen 1 permease becomes undetectable when the lactate production approaches about 8-10 $\mathrm{g} \mathrm{l}^{-1}$, suggesting a possible saturation of the Jen 1 transport mechanism.

In this respect, we did not try to further over-express the JEN1 gene because it has been shown that its over-expression using a multicopy plasmid did lead to an impaired growth [28].

It has been recently suggested that the export of lactate from recombinant yeast is an ATP-dependent process [10]. This extra energy required for the export of lactate could justify the lower biomass yield we generally observed for host cells producing a higher amount of lactate; Figure 4 for example compares the biomass values reached by two strains producing different amounts of lactate, being 2,4 $\left(\mathrm{OD}_{660}\right)$ for the strain transformed with the L. plantarum $L D H$ or $2,1\left(\mathrm{OD}_{660}\right)$ for the same strain transformed with the same $L D H$ gene and the $S$. cerevisiae JEN1.

In this respect, it is important to underline that an opposite behaviour can be obtained following the expression of the mutated L. plantarum LDH gene. In fact, in this case we observed a better lactic acid production/productivity and a better biomass production, being 2,4 $\left(\mathrm{OD}_{660}\right)$ for the strain transformed with the L. plantarum LDH or 2,6 $\left(\mathrm{OD}_{660}\right)$ the same host strain, but transformed with the mutated $L D H$ gene. However, it should be also noted that a similar ethanol production and a higher glucose consumption rate have been obtained too. More investigations are required to better understand the biological background of this behaviour. 


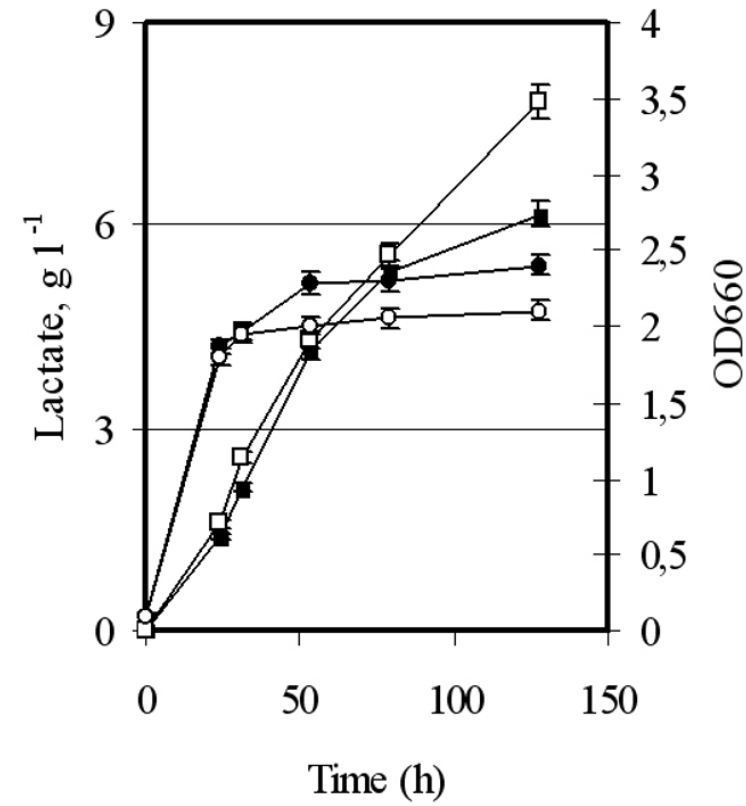

Figure 4

Effect of JENI expression on lactate production in recombinant GRF I 8 U host cells. S. cerevisiae GRFI8U cells transformed with the $L$. plantarum LDH (control; closed symbols) or co-transformed with the $L$. plantarum $L D H$ and the endogenous JENI genes (open symbols) were shake-flask grown in glucose $2 \% \mathrm{wv}^{-1}$ minimal selective medium till stationary phase. Samples were collected at indicated times (h) for optical density (OD $660 \mathrm{~nm}$, circles) and lactate $\left(\mathrm{g} \mathrm{l}^{-1}\right.$, squares) determinations.

\section{Conclusion}

Evolution has produced a huge variety of micro-organisms living in radically different environments. In particular, some of these micro-organisms have evolved metabolic pathways leading to the synthesis of potentially useful compounds that are difficult to produce from the chemical industry or that are environmentally harmful to manufacture. Generally speaking, the fundamental basis of evolution is the need to survive and reproduce, not to produce potentially important and commercially valuable products. Indeed, interesting metabolites are very often produced from wild type micro-organisms in such low concentrations that biotechnological exploitation is impractical. The ability to select mutants or to develop organisms by means of rDNA technologies to enable fast and environmentally friendly productions of these products has the obvious potential to revolutionize the biotechnological industry. The basic idea of metabolic engineering is to increase the flux through the selected metabolic pathway by (i) deleting (where possible) the competing branch pathways leading to the accumulation of by-products and/or by (ii) over-expressing the proteins catalysing rate-limiting steps and thereby removing bottlenecks. However, metabolic control analysis (MCA) theory teaches that, under stationary conditions, these bottlenecks do not exist. Generally speaking, all of the enzymes along a pathway are more or less equally ratelimiting [29].

As already underlined, not only for the production of important metabolites, but also for a better understanding of the fundamentals of cell biology, detailed studies are required. In this respect, we tried to modulate the lactate production and yield by improving the efficiency of the last (i.e., lactate transport) and the penultimate (i.e., Ldh activity) steps of the pathway leading to the accumulation of lactate from pyruvate. In fact, MCA also anticipates that a bottleneck situation sometimes could hold true for enzymes at the beginning and/or at the end of a pathway, i.e., the steps controlling the starting of the pathway and the removal of the final product [29].

A yield as high as $0,52 \mathrm{~g} \mathrm{~g}^{-1}$ can be reached forcing the metabolic flux towards the accumulation of the final product without any disruption and/or limitation of the other pathways competing for the same substrate. Figure 6, summarizes the production and yield values that can be achieved from the same S. cerevisiae strain (GRF18U) bearing different LDH growing under the same physiological conditions on $2 \% \mathrm{wv}^{-1}$ glucose-YNB.

Concluding, in this manuscript we proved that a high redirection of the glycolytic flux can be also obtained by modulating the last and the second last steps of the pathway leading to the extracellular accumulation of lactate from glucose. In this respect, and to the best of our knowledge, higher redirections of the glycolityc flux have never been obtained before without any disruption and/or limitation of the competing pathways.

\section{Methods}

Yeast strains, media and transformation

The $S$. cerevisiae strains used in this study were GRF18U

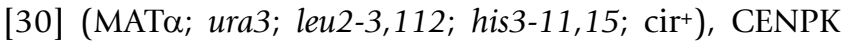
113-11C (MATa ura3-52; his3-11,15; cir $^{+}$) (see, as an example [31]), W303-1A (MATa; ade2-1; ura3-1; leu2-3, 112; his3-11, 15; trp1-1; can1-100) [32] and MB11 (MATa; ade2-101; ura3-52; lys2-801; his3-4200; trp1- 1 ; can1) [33].

Yeast cultures were shake-flask grown in minimal synthetic medium $\left(0.67 \% \mathrm{wv}^{-1} \mathrm{YNB}\right.$ Biolife without amino acids) with $2 \% \mathrm{wv}^{-1}$ of glucose as carbon source. When required, supplements such as leucine, uracil and histidine were added to a final concentration of $50 \mathrm{mg} \mathrm{l}^{-1}$. The 


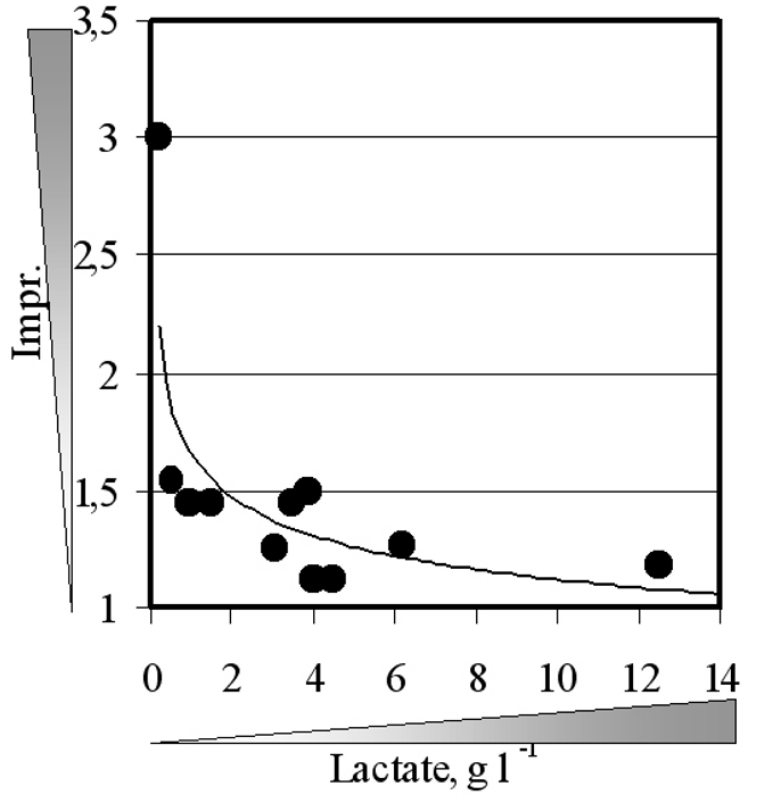

\section{Figure 5}

JENI effect decreases for high lactate productions. Different yeast strains (see also Table 2) transformed with the $L$. casei or L. plantarum LDH genes (i.e., controls) or cotransformed with the same $L D H$ and the S. cerevisiae JENI genes (see also Table I) were shake-flask grown in glucose $2 \%$ or $5 \% \mathrm{wv}^{-1}$ minimal selective medium till stationary phase. In abscissa are reported the highest lactate production determined, while in the ordinate are reported the improvements observed. The improvement value represents the ratio between the highest lactate production observed in the strain co-expressing the $L D H$ gene and the Jen I permease and the same strain expressing only the $L D H$ gene.

cultures were repeated independently (at least) three times, samples were taken at different times for the determination of growth parameters, metabolite production, nutrient consumption, enzymatic activities and protein level.

Transformation of $S$. cerevisiae strains was performed according to the LiAc/PEG/ss-DNA protocol [34]. The yeasts were transformed with one or more of the constructs described below, together with the respective empty plasmid(s). For each set of transformation, independent clones (at least 4) were initially tested and lactate levels determined, showing no significative differences among the independent clones.

\section{Genes amplification, mutagenesis and expression plasmid construction}

For the expression of the different heterologous LDH activities and for the over-expression of the S. cerevisiae lactate transporter Jen1, yeast expression plasmids of the series named "pYX" (R\&D Systems Wiesbaden, Germany) have been used. In these plasmids, the cassette for heterologous protein expression is based on the constitutive $S$. cerevisiae TPI promoter and the respective polyA, interspaced by the multi-cloning site (MCS), exploited for the sub-cloning of the genes of interest. The selection is based on different $S$. cerevisiae auxotrophic markers (in the present study always indicated in parenthesis, see also Table 1). In particular, the series of plasmids here utilised are all integrative, and the efficiency of integration was optimised by linearizing the plasmids before the yeast transformation, exploiting a unique site present in the sequence of the auxotrophic marker.

The full length Bos taurus (bovine) LDH-A coding sequence was PCR amplified from the plasmid pLDH12 [35] and inserted in the pALTER-1 (Promega) vector as already described [36]. From the resulting plasmid pVC1 the bovine $L D H$ was sub-cloned into the commercially available yeast integrative vector pYX012 (URA3 marker) generating the expression plasmid $\mathrm{pB} 1$. Alternatively, the bovine $L D H$ gene was sub-cloned into the integrative plasmid pYX022 (HIS3 marker) and pYX042 (LEU2 marker), generating the plasmids pB2 and pB3, respectively. For the described expression plasmids, the enzyme coding sequences were all EcoRI/SalI excised, and sub-cloned in the receiving expression vectors equally opened.

The Bacillus megaterium and Bacillus stearothermophylus $L D H$ genes (sequences available at the accession $n$. M22305 and M19396 GenBAnk, respectively) were PCR amplified from genomic DNA of the respective strains obtained by using the Invisorb Spin Bacteria DNA Mini Kit (Invitek), following manufacturer's instructions. The following primers were designed and used: $L D H B M$ fw: $5^{\prime}$ ACA AAT GAA AAC ACA ATT TAC ACC AAA AAC 3' LDHBM rev: 5' ATG TTA CAC AAA AGC TCT GTC GC 3'; LDHBSt fw: 5' AAT GAA AAA CAA CGG TGG AGC CCG 3' LDHBSt rev: 5 ' tgc ctc atc gcg taa aag cac gg 3'. The respective unique fragments obtained were sub-cloned in the vector pSTblue-1 utilising the Perfectly Blunt ${ }^{\circledR}$ Cloning Kit (Novagene) and checked by sequencing analysis. From the obtained plasmids pSTBMLDH and pSTBSTLDH, the coding sequences were EcoRI excided and subsequently sub-cloned into the $S$. cerevisiae integrative expression vector pYX012 (URA3 marker), EcoRI opened and de-phosphorylated. The resulting expression plasmids were named: pBME2 and pBST2, respectively. 
The Lactobacillus casei LDH gene was PCR amplified and subsequently sub-cloned into the yeast integrative vector pYX012 (URA3 marker) generating the expression plasmid pLC5, or in pYX022 (HIS3 marker) generating the expression plasmid pLC7, as previously described [30].

The Lactobacillus plantarum LDH gene (sequence available at the accession n. X70926, GenBAnk) was PCR amplified from genomic DNA obtained from the strain ATCC 8014 by using the Invisorb Spin Bacteria DNA Mini Kit (Invitek), following manufacturer's instructions. The following primers were designed and used: $L D H ~ f w: 5^{\prime}$ TGA CTT ATT ATG TCA AGC AT 3', where a mismatch was introduced in order to substitute the bacterial start codon TTG with ATG, correctly recognised by $S$. cerevisiae, and LDH rev: 5' ATC GTA TGA AAT GAT TAT TTA TT 3'. The unique fragment obtained was sub-cloned in the vector pSTblue-1 utilising the Perfectly Blunt ${ }^{\circledR}$ Cloning Kit (Novagene) and sequenced. In the amplified sequence four bp resulted substituted in respect to the original sequence, but only two of them generated two conservative aa substitutions (H54D and C302S, respectively). From the obtained and sequenced plasmid pSTplLDH, the coding sequence of $p l L D H$ was EcoRI excised and subsequently sub-cloned into the $S$. cerevisiae integrative expression vector pYX022 (HIS3 marker), pYX012 (URA3 marker) EcoRI opened and de-phosphorylated. The resulting expression plasmids were named p022TLP and p012TLP, respectively.

The plLDH was then also mutagenised according to the suggestions derived from modelling studies (see below). In particular, the aa 94 Asp (D) was changed into Gly (G) by a double bp substitution changing the triplet GAC into GGT. The mutagenesis was made by the Altered Sites II in vitro Mutagenesis Systems (Promega) using plasmid pSTplLDH as template DNA and complementary primer pairs that encode the desired amino acid replacement, following manufacturer's instructions. The sequence change was confirmed by DNA sequence analysis and finally subcloned into plasmids of the already described series "pYX". In particular, the modified sequence was inserted in the plasmid pYX022 (HIS3 marker) or in the plasmid pYX012 (URA3 marker), resulting in the yeast expression plasmids p022TLPD94G and p012TLPD94G, respectively.

The DNA sequence of JEN1 (available at the accession n. U24155, GenBank) was PCR amplified with the following primers: Tony s: 5' ACT GCT ACT GAA AAT ATG TCG TCG T 3 ' and Tony as: 5' AGT GAT TAA ACG GTC TCA ATA TGC TC 3' starting from $S$. cerevisiae genomic DNA extracted as described (slightly modified from [37]). The unique fragment obtained was sub-cloned in the vector pSTblue-1 and sequenced. From the obtained plasmid, the coding sequence of ScJEN1 was EcoRI excided and subsequently sub-cloned into the $S$. cerevisiae integrative expression vectors pYX012 (URA3 marker) and pYX022 (HIS3 marker) EcoRI opened and de-phosphorylated, generating the plasmids p012Jen 1 and p022Jen1, respectively.

DNA manipulations, transformation and cultivation of Escherichia coli (DH5 $\alpha \mathrm{F}^{\prime}$ ( $\phi$ 80d lacZ $\triangle \mathrm{M} 15, \Delta$ (lacZYAargF), U169, deo, rec1, end1, sup44, $\lambda$, THI-1, gyrA96, relA1 and Novablue Competent Cells (Novagene) were performed following standard protocols [38]. All the restriction and modification enzymes used were from New England Biolabs (Hitchin, Herts, UK) or from Roche Diagnostics (Mannheim, Germany).

\section{Measurement of cell concentration, metabolites and enzymatic activities}

Independent recombinant yeast transformants were shake-flasks cultured in minimal medium. During the cultures, followed up to stationary phase, samples were collected at regular time intervals. Cell concentration was determined by measuring the optical density at $660 \mathrm{~nm}$ or the cell number by a Coulter Counter determination [39].

Glucose, ethanol, L(+)-lactate were determined by using diagnostic kits (Boehringer Mannheim cat $\mathrm{n}^{\circ} 148261$, 716251 and 176290 , respectively) according to manufacturer's instructions. The lactate yields were calculated by linear regressions obtained by plotting the grams of glucose consumed in the course of fermentation processes versus the grams of lactate produced.

For all LDH activities, samples were prepared as follows: about $10^{8}$ cells were harvested, washed in ice-cold water and re-suspended in $50 \mathrm{mM}$ phosphate buffer $\mathrm{pH} 7.5$, Glycerol 20\%, PMSF $1 \mathrm{mM}$ and protease inhibitors (Complete EDTA-free Protease inhibitor cocktail tablets, Roche). Cells were broken with 5 cycles of vigorous vortexing in presence of glass beads (diam. 400-600 $\mu \mathrm{m}$, Sigma) at $4{ }^{\circ} \mathrm{C}$. After centrifugation, protein extracts concentration was determined (Bradford, Biorad).

For bovine LDH activity, about $0.2 \mathrm{mg}$ of extract were tested using the Sigma kit DG1340-UV, according to manufacturer's instructions.

For all bacterial LDH activities determination, except the L. plantarum one, cellular extract $(0.05 \mathrm{ml}$ of properly diluted samples) were incubated with $0.01 \mathrm{ml}$ of $12.8 \mathrm{mM}$ $\mathrm{NADH}, 0.1 \mathrm{ml}$ of $2 \mathrm{mM}$ fructose1,6-diphosphate, $0.74 \mathrm{ml}$ of $50 \mathrm{mM}$ acetate buffer $(\mathrm{pH} 5.6)$ and $0.1 \mathrm{ml}$ sodium pyruvate $100 \mathrm{mM}$. The L. plantarum LDH activity was almost identically determined, omitting the not necessary cofactor fructose 1,6-diphosphate, as previously described 


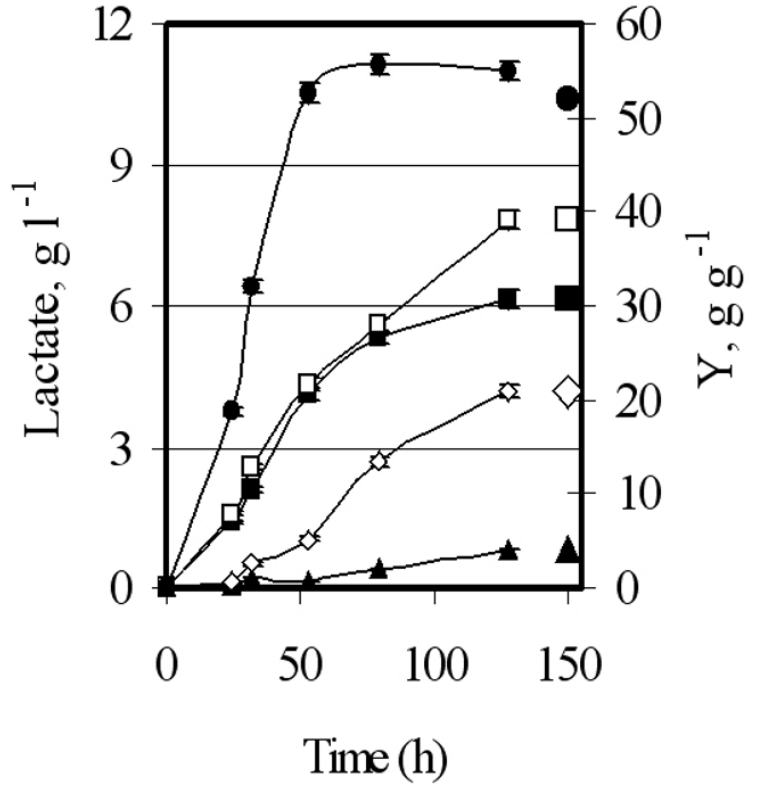

\section{Figure 6}

Lactate production and yield obtained from recombinant GRF I $8 U$ host cells. Different recombinant S. cerevisiae GRFI8U cells were shake-flask grown in glucose $2 \%$ $\mathrm{Wv}^{-1}$ minimal selective medium till stationary phase. Samples were collected at indicated times $(\mathrm{h})$ for lactate $\left(\mathrm{g} \mathrm{I}^{-1}\right)$ and yield (gram of lactate produced per gram of glucose consumed; values are here below reported) determinations. $\left({ }^{\wedge}\right)$ B. taurus $L D H$ yield $4 \% \pm 0.2 \%\left(0^{\circ}\right) \mathrm{L}$. casei $L D H$ yield $21 \% \pm$ $0.4 \%(\square) L$. plantarum $L D H$ yield $31 \% \pm 0.5 \%(\square)$ L. plantarum $L D H+S C J E N I$ yield $39 \% \pm 0.5 \%(\bigcirc)$ Mutated L. plantarum $L D H$. yield $52 \% \pm 0.7 \%$

[40]. LDH activity was assayed as micromoles of NADH oxidized per min, per mg of total protein extract, at 340 $\mathrm{nm}, 25^{\circ} \mathrm{C}$.

\section{Simulations}

The computational investigation has been carried out using the X-ray structure of Ldh from Squalus acanthias, chosen because both of the holo and apo structures are available (pdb codes: 3LDH, 6LDH, respectively. Web site: http://www.rcsb.org/pdb). However, results are expected to be valid also for Ldh from L. planctarum, due to the high sequence similarity between the two proteins (not shown).

Molecular Mechanics (MM) optimizations were performed using the GROMACS simulation software package [41], implemented on a parallel architecture. MM runs consisted in 1000 steepest descent cycles followed by 10000 conjugate gradient steps.

Initially, cofactor (NADH) and substrate (pyruvate) have been removed from the X-ray structure, in order to simplify the computational investigation of the conformational properties of the protein. Since the movement of the catalytic loop takes place on a relatively low time scale $\left(\mathrm{kcat}=250 \mathrm{~s}^{-1}\right)$, average value among several species [20] standard Molecular Dynamics simulations could not be used to investigate the conformational rearrangement. Instead, the conformational properties of the catalytic loop have been investigated by iterative modification of selected torsional angles, followed by Molecular Mechanics optimization. In particular, analysis of the X-ray structures of the apo and holo form of Ldh suggests that the conformational rearrangement of the catalytic loop mainly implies modification of two protein torsion angles ( $\mathrm{phi}_{96}$ and $\mathrm{phi}_{97}, \mathrm{~N}-\mathrm{C}_{\mathrm{alfa}}$ ), which have been systematically rotated in steps of 10 degrees. The resulting structures were optimised by $\mathrm{MM}$ in order to obtain stationary points on the Potential Energy Surface (PES), thus allowing to sample the PES of the protein structure along the reaction coordinate corresponding to the relevant movement of the catalytic loop.

\section{Antibody development against L. plantarum LDH and protein level analysis}

Different commercially available antibodies against LDH were tested, but none of them is specific for bacterial LDHs and none of them resulted sufficiently specific for plLDH detection in our host system. By utilizing the tool Syfpeithi http://www.bmi-heidelberg.com/ we individuated the peptide DCKDADLVVITAGAPQKPGE (from aa 71 to aa 90 of the aminoacidic sequence of the protein) as the preferred immunogen to develop polyclonal antibody. The above mentioned peptide and the corresponding antibody (as immune serum) were synthesized and developed, respectively, by Primm Italia http:// www.primmbiotech.com.

LDH expression levels were analyzed by Western Blot. From each point of the above described kinetics of growth, a culture volume corresponding to $10^{8}$ cells was harvested by centrifugation, and crude extracts were prepared by following the trichloroacetic acid protocol [42] and resuspending the final protein extract in $150 \mu \mathrm{l}$ of Laemmli buffer [43]. Protein extracts corresponding to $10^{7}$ cells were loaded on a $12 \%$ polyacrylamide gel (SDSPAGE); after separation, proteins were blotted to nitrocellulose membranes and immunodecorated. LDH levels were detected using the developed primary rabbit polyclonal antibody, (dilution 1:250) and a secondary anti-rabbit IgG horseradish peroxidase-conjugated (Amersham Pharmacia Biotech, UK; dilution 1:5000) antibody. The 
immunoreactive protein bands were developed using the Super Signal West Pico Western blotting system (Pierce), according to the manufacturer's instructions.

\section{Authors' contributions}

PB participated in the design of the study and planned and carried out the experimental work including plasmid and strain construction, yeast cultivation and data analysis, western blot immunoassays and enzymatic activity determination; participated in drafting the manuscript.

MS and MV participated in the design of the study and in molecular biology experiments.

LDG and GZ designed and performed the modeling studies and simulations, suggesting the point mutation.

DM participated in the design of this study and in data interpretation.

DP designed the whole study, performed data interpretation and drafted the manuscript.

\section{All authors read and approved the final manuscript.}

\section{Acknowledgements}

This work was partially supported by Tate \& Lyle North America, Decatur, Illinois and F.A.R. 2005 to DP. The work related to the mutated LDH was partially supported by the Project BIOCDM (Biotech Clusters Development and Management) Interreg IIIC - REGINS, 2005 to DP. The authors are indebted to Marina Vai, Vittorio Carrera and Luca Brambilla for helping with some of the presented cloning work and experiments and to Carla Smeraldi for language corrections throughout the manuscript.

\section{References}

I. Stephanopoulos G: Metabolic fluxes and metabolic engineering. Metab Eng 1999, I(I): I-II.

2. Kramer M, Bongaerts J, Bovenberg R, Kremer S, Muller U, Orf S, Wubbolts $M$, Raeven $L$ : Metabolic engineering for microbial production of shikimic acid. Metab Eng 2003, 5(4):277-83.

3. Thykaer J, Nielsen J: Metabolic engineering of beta-lactam production. Metab Eng 2003, 5(1):56-69.

4. Thelen JJ, Ohlrogge JB: Metabolic engineering of fatty acid biosynthesis in plants. Metab Eng 2002, 4(I): 12-2I.

5. Bongaerts J, Kramer M, Muller U, Raeven L, Wubbolts M: Metabolic engineering for microbial production of aromatic amino acids and derived compounds. Metab Eng 2001, 3(4):289-300.

6. Dequin S, Barre P: Mixed lactic acid-alcoholic fermentation by Saccharomyces cerevisiae expressing the Lactobacillus casei L(+)-LDH. Biotechnology (NY) I994, I2(2): 173-7.

7. Porro D, Brambilla L, Ranzi BM, Martegani E, Alberghina L: Development of metabolically engineered Saccharomyces cerevisiae cells for the production of lactic acid. Biotechnol Prog 1995, II(3):294-8.

8. Ansanay V, Dequin S, Camarasa C, Schaeffer V, Grivet JP, Blondin B, Salmon JM, Barre P: Malolactic fermentation by engineered Saccharomyces cerevisiae as compared with engineered Schizosaccharomyces pombe. Yeast 1996, I2(3):215-25.

9. Skory CD: Lactic acid production by Saccharomyces cerevisiae expressing a Rhizopus oryzae lactate dehydrogenase gene. J Ind Microbiol Biotechnol 2003, 30(I):22-7.

10. van Maris AJ, Winkler AA, Porro D, van Dijken JP, Pronk JT: Homofermentative lactate production cannot sustain anaerobic growth of engineered Saccharomyces cerevisiae: possible con- sequence of energy-dependent lactate export. Appl Environ Microbiol 2004, 70(5):2898-905.

II. Colombie S, Sablayrolles JM: Nicotinic acid controls lactate production by KI-LDH: a Saccharomyces cerevisiae strain expressing a bacterial LDH gene. J Ind Microbiol Biotechnol 2004, 3I(5):209-I5.

12. Ishida N, Saitoh S, Tokuhiro K, Nagamori E, Matsuyama T, Kitamoto $\mathrm{K}$, Takahashi $\mathrm{H}$ : Efficient production of L-Lactic acid by metabolically engineered Saccharomyces cerevisiae with a genome-integrated L-lactate dehydrogenase gene. Appl Environ Microbiol 2005, 7 I (4): 1964-70.

13. Saitoh S, Ishida N, Onishi T, Tokuhiro K, Nagamori E, Kitamoto K, Takahashi $\mathrm{H}$ : Genetically engineered wine yeast produces a high concentration of L-lactic acid of extremely high optical purity. Appl Environ Microbiol 2005, 7 I (5):2789-92.

14. Porro D, Bianchi MM, Brambilla L, Menghini R, Bolzani D, Carrera V, Lievense J, Liu CL, Ranzi BM, Frontali L, Alberghina L: Replacement of a metabolic pathway for large-scale production of lactic acid from engineered yeasts. Appl Environ Microbiol 1999, 65(9):42।I-5

15. Bianchi MM, Brambilla L, Protani F, Liu CL, Lievense J, Porro D: Efficient homolactic fermentation by Kluyveromyces lactis strains defective in pyruvate utilization and transformed with the heterologous LDH gene. Appl Environ Microbiol 200I, 67( 12$): 5621-5$.

16. Porro D, Bianchi MM, Ranzi BM, Frontali L, Vai M, Winkler AA, Alberghina $L$ : Yeast strains for the production of lactic acid. 1999. PCT WO 99//4335

17. Branduardi P, Valli M, Brambilla L, Sauer M, Alberghina L, Porro D: The yeast Zygosaccharomyces bailii: a new host for heterologous protein production, secretion and for metabolic engineering applications. FEMS Yeast Res 2004, 4(4-5):493-504.

18. Benninga $\mathrm{H}$ : A history of lactic acid making Kluwer Academic Publishers: Dordrecht, The Netherlands; 1990.

19. Garvie El: Bacterial Lactate Dehydrogenases. Microbiol Rev 1980, 44(I): 106-139.

20. Clarke AR, Wigley DB, Chia WN, Barstow D, Atkinson T, Holbrook $\mathrm{JJ}$ : Site-directed mutagenesis reveals role of mobile arginine residue in lactate dehydrogenase catalysis. Nature 1986, 324:699-702.

21. Abad-Zapatero C, Griffith JP, Sussman JL, Rossmann MG: Refined crystal structure of dogfish M4 apo-lactate dehydrogenase. J Mol Biol 1987, 198(3):445-67.

22. Casal M, Paiva S, Andrade RP, Gancedo C, Leao C: The lactate-proton symport of Saccharomyces cerevisiae is encoded by JENI. J Bacteriol 1999, I8I(8):2620-3.

23. Andrade RP, Casal M: Expression of the lactate permease gene JENI from the yeast Saccharomyces cerevisiae. Fungal Genet Biol 200I, 32(2): 105-II.

24. Lodi T, Fontanesi F, Guiard B: Co-ordinate regulation of lactate metabolism genes in yeast: the role of the lactate permease gene JENI. Mol Genet Genomics 2002, 266(5):838-47.

25. Andrade RP, Kotter P, Entian KD, Casal M: Multiple transcripts regulate glucose-triggered mRNA decay of the lactate transporter JENI from Saccharomyces cerevisiae. Biochem Biophys Res Commun 2005, 332(I):254-62.

26. Makuc J, Paiva S, Schauen M, Kramer R, Andre B, Casal M, Leao C, Boles $E$ : The putative monocarboxylate permeases of the yeast Saccharomyces cerevisiae do not transport monocarboxylic acids across the plasma membrane. Yeast 200I, 18(12): $\mid$ | $3 \mid-43$.

27. Soares-Silva I, Schuller D, Andrade RP, Baltazar F, Cassio F, Casal M: Functional expression of the lactate permease Jen Ip of Saccharomyces cerevisiae in Pichia pastoris. Biochem J 2003, 376:78I-787.

28. de Kerchove d'Exaerde A, Supply P, Goffeau A: Subcellular traffic of the plasma membrane $\mathrm{H}(+)$-ATPase in Saccharomyces cerevisiae. Yeast 1996, I 2(10):907-916.

29. Brown AJP: Control of metabolic flux in yeasts and fungi. Volume 15. TIBTECH Elsevier Science Ltd; 1997:445-447.

30. Brambilla L, Bolzani D, Compagno C, Carrera V, van Dijken JP, Pronk JT, Ranzi BM, Alberghina L, Porro D: NADH reoxidation does not control glycolytic flux during exposure of respiring Saccharomyces cerevisiae cultures to glucose excess. FEMS Microbiol Lett |999, | 7|: | 33-140. 
31. Van Dijken JP, Bauer J, Brambilla L, Duboc P, Francois JM, Gancedo C, Giuseppin MLF, Heijnen JJ, Hoare M, Lange HC, Madden EA, Niederberger P, Nielsen J, Parrou JL, Petit T, Porro D, Reuss M, Van Riel N, Rizzi M, Steensma HY, Verrips CT, Vindelov J, Pronk JT: An interlaboratory comparison of physiological and genetic properties of four Saccharomyces cerevisiae strains. Enzyme Microb Technol 2000, 26(9-10):706-7|4.

32. Thomas BJ, Rothstein R: Elevated recombination rates in transcriptionally active DNA. Cell I989, 56(4):619-630.

33. Davis ES, Becker A, Heitman J, Hall MN, Brennan MB: A yeast cyclophilin gene essential for lactate metabolism at high temperature. PNAS 1992, 89(23): I I 165-73.

34. Gietz RD, Woods RA: Transformation of yeast by the Liac/ss carrier DNA/PEG method. Methods in Enzymology 2002, 350:87-96.

35. Ishiguro N, Osame S, Kagiya R, Ichijo S, Shinagawa M: Primary structure of bovine lactate dehydrogenase-A isozyme and its synthesis in Escherichia coli. Gene 1990, 9 I(2):28I-5.

36. Porro D, Brambilla L, Ranzi BM, Martegani E, Alberghina L: Development of metabolically engineered Saccharomyces cerevisiae cells for the production of lactic acid. Biotechnol Prog 1995, I I(3):294-8.

37. Hoffman , Winston : Rapid Genomic Prep. Protocol 1987 [http:// www.fhcrc.org/labs/gottschling/yeast/qgprep.html].

38. Sambrook J, Fritsch EF, Maniatis T: Molecular Cloning: A Laboratory Manual Edited by: second. Cold Spring Harbor Laboratory Press, Cold Spring Harbor, NY; 1989.

39. Vanoni M, Vai M, Popolo L, Alberghina L: Structural heterogeneity in populations of the budding yeast Saccharomyces cerevisiae. J Bacteriol 1983, I56:1282-129|.

40. Bernard N, Ferain T, Garmyn D, Hols P, Delcour J: Cloning of the D-lactate dehydrogenase gene from Lactobacillus delbrueckii subsp. bulgaricus by complementation in Escherichia coli. FEBS Lett I99|, 290(I-2):6I-4.

4I. van der Spoel D, van Buuren AR, Apol E, Meulenhoff PJ, Tieleman DP, Sijbers ALTM, Hess B, Feenstra KA, Lindhal E, van Drunen R, Berendsen HJC: Gromacs User Manual version 3.I.I,. 2002 [http:// www.gromacs.org]. Nijenborgh 4, 9747 AG Groningen, The Netherlands

42. Surana $U$, Amon A, Dowzer C, McGrew J, Byers B, Nasmyth K: Destruction of the CDC28/CLB mitotic kinase is not required for the metaphase to anaphase transition in budding yeast. EMBO J 1993, I2:1969-1978.

43. Laemmli UK: Cleavage of structural proteins during the assembly of the head of bacteriophage T4. Nature 1970, 227:680-685.

44. van Urk H, Schipper D, Breedveld GJ, Mak PR, Scheers WA, van Dijken JP: Localization and kinetics of pyruvate-metabolizing enzymes in relation to aerobic alcoholic fermentation in Saccharomyces cerevisiae CBS 8066 and Candida utilis CBS $62 \mathrm{I}$. Biochem Biophys Acta 1989, 992:78-86.

\section{Publish with Bio Med Central and every scientist can read your work free of charge}

"BioMed Central will be the most significant development for disseminating the results of biomedical research in our lifetime. "

Sir Paul Nurse, Cancer Research UK

Your research papers will be:

- available free of charge to the entire biomedical community

- peer reviewed and published immediately upon acceptance

- cited in PubMed and archived on PubMed Central

- yours - you keep the copyright

Submit your manuscript here:

http://www.biomedcentral.com/info/publishing_adv.asp
BioMedcentral 